\title{
Effects of lisinopril on cardiorespiratory, neuroendocrine, and renal function in patients with asymptomatic left ventricular dysfunction
}

John G F Cleland, Dilip Shah, Shirley Krikler, Athanase Dritsas, Petros Nihoyannopoulos, Gary Frost, Celia M Oakley

\begin{abstract}
Objective-To determine the cardiac, renal, and neuroendocrine effects of lisinopril in men with untreated, symptom free left ventricular systolic dysfunction. Design-A randomised, double blind cross over trial with six week treatment periods to compare lisinopril (10 $\mathrm{mg} / \mathrm{day})$ and matching placebo.
\end{abstract}

Setting-Hospital outpatient department. Patients-Patients with pronounced systolic dysfunction on cross sectional echocardiography due to myocardial infarction at least six months previously, without angina and with no or minimal breathlessness. Eighteen men were identified of whom 15 completed the study. Interventions-Lisinopril (10 $\mathrm{mg})$ or placebo given once daily by mouth.

Main outcome measures-Primary: oxygen consumption at peak exercise. Secondary: resting cardiac function as measured by radionuclide ventriculography and echocardiography, renal function estimated radioisotopically, and plasma indices of neuroendocrine activity. Results-Compared with placebo, lisinopril increased (mean (SD)) peak oxygen consumption during exercise $(19 \cdot 8(3 \cdot 1) \mathrm{ml} / \mathrm{kg} / \mathrm{min} v 21 \cdot 4(3 \cdot 2) \mathrm{ml} / \mathrm{kg} /$ min; p<0.003). Lisinopril did not improve indices of cardiac function at rest. It reduced plasma concentrations of angiotensin II (median values $7 \mathrm{pg} / \mathrm{ml}$ to $5 \mathrm{pg} / \mathrm{ml}$ p $<0.02$ ), aldosterone (median values $113 \mathrm{pg} / \mathrm{ml}$ to $66 \mathrm{pg} / \mathrm{ml}$; $<0.05)$ and atrial natriuretic peptide (median values $69 \mathrm{pg} / \mathrm{ml}$ to $40 \mathrm{pg} / \mathrm{ml}$; $<<0.04$ ), but noradrenaline and antidiuretic hormone concentrations did not change. Renal blood flow increased and glomerular filtration rate declined.

Conclusions-Even before the onset of heart failure lisinopril improves the cardiopulmonary response to exercise in patients with systolic ventricular dysfunction.

(Br Heart f 1993;69:512-515)

Patients with ventricular dysfunction that has progressed to overt heart failure have a poor prognosis. Even in those with very mild heart failure about $50 \%$ will die within five years. ${ }^{12}$ Preservation of ventricular function and prevention of progression to overt heart failure are important goals in the management of symptom free ventricular dysfunction that are likely to improve prognosis.

The Studies of Left Ventricular? Dysfunction showed that enalapril can delay or prevent the onset of heart failure ines patients with compromised left ventricular function, ${ }^{3}$ and slow the deterioration in the patients' condition thereafter, thereby reduc. ing mortality. These studies, however, haves not generally considered the mechanisms by which such benefits were derived.

Previous studies have indicated that the renin angiotensin aldosterone system is not significantly activated in patients with ventric옥 ular dysfunction untreated by diuretics, $\overrightarrow{ }$ which might suggest that such patients would $€$ have little to gain from an angiotensin con verting enzyme inhibitor. ${ }^{4}$ Evidence from studies with animals, however, suggests thate although the RAA system activity seems nor mal in untreated ventricular dysfunction ie may be tonically suppressed by subclinicap salt and water retention rather than merelyo not activated. ${ }^{5}$

The aims of our study were to investigate the effects of the ACE inhibitor lisinopril on cardiac, neuroendocrine and renal function ina group of patients with considerablyo impaired ventricular function due tôे ischaemic heart disease.

\section{Patients and methods}

Eighteen men, mean (SD) age 58 (7) years] with minimal or no symptoms of heart failureo but with echocardiographic evidence of con? siderable left ventricular dysfunction were identified. Before the screening visit for inclu sion in the study, one patient died unexpectedly during sleep. The mean (SD) leff ventricular ejection fraction measured bx心 radionuclide ventriculography was $39.9 \%$ $(10 \cdot 2 \%)$ at baseline in the remaining $1 \%$ patients who started the study. Ejection fraction in eight age and sex matched contro ${ }^{+}$ patients who had had a coronary bypass but who had no evidence of myocardial infarction or ventricular dysfunction was $66.0 \%(7 \cdot 9 \%) \stackrel{?}{\stackrel{P}{\mathbb{P}}}$ All patients had had a previous myocardiaf infarction that had affected the anterior (10), inferior (three), or both territories (four). Nœ patient had had a myocardial infarction with in one year of the study. Eleven had has coronary revascularisation, but none within six months of the study. The right atrial appendage was not removed at the time of operation. No patient had evidence of reversible ischaemia or significant mitral 
regurgitation. Patients were excluded if they were receiving a diuretic or other cardioactive medication or had significant pulmonary or systemic disease. All patients were in sinus rhythm.

\section{STUDY DESIGN}

After agreeing to participate patients were placed on a metabolic diet containing 100 mmol of sodium and $40 \mathrm{mmol}$ of potassium for three days before the baseline tests.

Venous samples, with the patient in the supine position, were taken for measurement of plasma concentrations of renin, angiotensin II, aldosterone, antidiuretic hormone, catecholamines, and atrial natriuretic peptide, ${ }^{67}$ and the estimation of serum electrolytes, urea, and creatinine.

Ventricular function at rest was assessed by $M$ mode, Doppler, and cross sectional echocardiography and by gated blood pool scanning. Stroke distance was calculated from the velocity time integral. Diastolic function was assessed by measurement of the duration of isovolumic relaxation calculated from the end of the aortic flow to the onset of mitral inflow and from the height of the $\mathrm{E}$ wave and the $\mathrm{E} / \mathrm{A}$ ratio on the mitral inflow Doppler signal.

Systolic function was further assessed by radionuclide left ventricular ejection fraction and fractional shortening from the echocardiogram.

Exercise testing was conducted with two tests of different intensity. A high intensity protocol was used to measure maximum cardiorespiratory performance and peak oxygen consumption. A low intensity protocol was used to more nearly simulate the type of exercise in which the patient might be engaged during normal daily activities. All patients underwent familiarisation with at least two exercise tests before inclusion in the study.

Renal function and the metabolic effects of lisinopril were assessed by radionuclide studies $^{8}$ and serial estimation of serum urea, electrolytes, and creatinine.

Subsequently patients entered a randomised, double blind, cross over study with six week treatment periods to compare lisinopril and matching placebo. Each patient received an initial $2.5 \mathrm{mg}$ dose of lisinopril or placebo at the start of each phase of the study and was monitored for six hours thereafter. Patients then received $5 \mathrm{mg} /$ day of lisinopril or matching placebo for two weeks. If the patient tolerated this dose and the systolic blood pressure was $>100 \mathrm{~mm} \mathrm{Hg}$ the patients then received $10 \mathrm{mg} /$ day of lisinopril or matching placebo for the remaining four weeks.

\section{STATISTICAL ANALYSIS}

Values given are mean (SD) where data are normally distributed. Mean, median, and range are quoted where data are not normally distributed. Only variables that seemed to show a significant change or were a primary end point of the study were formally tested for significance.
Variables were first tested for order or period effects; if such effects had been found, that variable would have been excluded from further statistical analysis. This was not necessary. The changes from baseline to the end of each treatment phase were compared. Student's $t$ test was used with prior logarithmic transformation of the data if they were not normally distributed.

Two patients were randomised but failed to complete the study (explained later). Neither outcome was thought to have influenced the outcome in favour of active treatment.

\section{Results}

CLINICAL OUTCOME

Fifteen patients completed the study. One patient decided not to participate further after completing the baseline tests, but before receiving any study medication. One patient completed the first six weeks of the study receiving lisinopril and improved his exercise performance, but developed dizziness while receiving placebo, stopped treatment some days before the two week visit, and was excluded from analysis.

No patient developed symptomatic hypotension after the first dose of lisinopril. All patients progressed to the higher dose of lisinopril.

\section{BASELINE STUDY RESULTS}

Tables 1 and 2 show that despite the lack of symptoms, exercise performance was impaired. Plasma concentrations of atrial natriuretic peptide were increased above the laboratory range but those of active renin, angiotensin II, aldosterone, and noradrenaline were not. Renal blood flow and glomerular filtration rate were well preserved.

\section{EFFECTS OF LISINOPRIL}

\section{Heart rate and blood pressure}

Lisinopril did not affect lying or standing blood pressure at rest or resting heart rate (table 1).

\section{Resting cardiac function}

Lisinopril did not alter resting cardiac volumes or measures of systolic or diastolic function (table 1).

\section{Renal function}

Treatment with lisinopril increased renal blood flow and reduced glomerular filtration rate (table 1).

\section{Exercise performance}

Table 2 shows that lisinopril did not affect duration of exercise during the low intensity protocol. Patients stopped for a variety of reasons during this protocol, mainly breathlessness or fatigue. With the high intensity protocol peak oxygen consumption was greater during treatment with lisinopril $(p<0.003)$, this was associated with a trend to improved exercise time $(p=0 \cdot 09)$. The most important limiting symptom during this test 
Table 1 Measurements (mean (SD)) of resting cardiac and renal function

\begin{tabular}{|c|c|c|c|}
\hline & Baseline & Lisinopril & Placebo \\
\hline $\begin{array}{l}\text { Heart rate } \\
\text { (beats/min) }\end{array}$ & $64(5)$ & $\begin{array}{l}67(6) \\
\mathrm{n}=15 ; \mathrm{nc}\end{array}$ & $66(3)$ \\
\hline $\begin{array}{l}\text { Systolic BP } \\
(\mathrm{mm} \mathrm{Hg})\end{array}$ & $134(12)$ & $\begin{array}{l}135(16) \\
\mathrm{n}=15 ; \mathrm{nc}\end{array}$ & $137(14)$ \\
\hline $\begin{array}{l}\text { Diastolic BP } \\
(\mathrm{mm} \mathrm{Hg})\end{array}$ & $78(6)$ & $\begin{array}{l}78(7) \\
\mathrm{n}=15 ; \mathrm{nc}\end{array}$ & $79(5)$ \\
\hline Ejection fraction (\%) & $39.4(9.5)$ & $\begin{array}{l}39 \cdot 7(9 \cdot 7) \\
\mathrm{n}=15 ; \mathrm{NS}\end{array}$ & $38 \cdot 7(10 \cdot 8)$ \\
\hline Echocardiographic LVEDD (mm) & $56(6)$ & $\begin{array}{l}56(7) \\
\mathrm{n}=13 ; \mathrm{nc}\end{array}$ & $55(6)$ \\
\hline Echocardiographic LVESD (mm) & $44(6)$ & $\begin{array}{l}43(6) \\
\mathrm{n}=13 ; \mathrm{nc}\end{array}$ & $43(6)$ \\
\hline Fractional shortening (\%) & $21(5)$ & $\begin{array}{l}24(7) \\
\mathrm{n}=13 ; \mathrm{nc}\end{array}$ & $21(7)$ \\
\hline Peak flow velocity $(\mathrm{cm} / \mathrm{s})$ & $76(8)$ & $\begin{array}{l}81(14) \\
\mathrm{n}=14 ; \mathrm{nc}\end{array}$ & $77(14)$ \\
\hline Stroke distance $(\mathrm{cm})$ & $11 \cdot 3(2 \cdot 0)$ & $\begin{array}{l}13 \cdot 1(3 \cdot 8) \\
\mathrm{n}=14: \mathrm{NS}\end{array}$ & $11 \cdot 3(2 \cdot 5)$ \\
\hline IVRT (ms) & $73(18)$ & $\begin{array}{l}70(6) \\
\mathrm{n}=10 ; \mathrm{nc}\end{array}$ & $79(14)$ \\
\hline E wave velocity $(\mathrm{cm} / \mathrm{s})$ & $50(10)$ & $\begin{array}{l}51(14) \\
\mathrm{n}=15 ; \mathrm{nc}\end{array}$ & $48(12)$ \\
\hline Time to peak filling (ms) & $68(17)$ & $\begin{array}{l}62(19) \\
\mathrm{n}=15 ; \mathrm{nc}\end{array}$ & 70 (19) \\
\hline $\mathrm{E} / \mathrm{A}$ & $1.08(0.77)$ & $\begin{array}{l}1 \cdot 08(0 \cdot 48) \\
n=15 ; n c\end{array}$ & $0.99(0.44)$ \\
\hline $\mathrm{GFR}(\mathrm{ml} / \mathrm{min})$ & $107(36)$ & $\begin{array}{l}97(23) \\
\mathrm{n}=12 ; \mathrm{p}=0.04\end{array}$ & $112(21)$ \\
\hline $\mathrm{RBF}(\mathrm{ml} / \mathrm{min})$ & $639(260)$ & $\begin{array}{l}803(386) \\
n=12 ; p=0.05\end{array}$ & $645(296)$ \\
\hline
\end{tabular}

BP, blood pressure; LVEDD and LVESD, left ventricular end diastolic and end systolic dimensions; IVRT, isovolumic relaxation time; E/A, early atrial filling wave velocities; GFR, glomerular filtration rate; $R B F$, renal blood flow; nc, significance not calculated.

Table 2 Exercise testing (mean (SD))

\begin{tabular}{lccc}
\hline & Baseline & Lisinopril & Placebo \\
\hline HIP exercise time (s) & $258(59)$ & $\begin{array}{l}275(50) \\
\mathrm{p}=0.09\end{array}$ & $259(67)$ \\
Peak $\mathrm{VO}_{2}(\mathrm{ml} / \mathrm{kg} / \mathrm{min})$ & $20 \cdot 8(3 \cdot 6)$ & $\begin{array}{l}21 \cdot 4(3 \cdot 2) \\
\mathrm{p}<0.003\end{array}$ & $19 \cdot 8(3 \cdot 1)$ \\
LIP exercise time (s) & $702(261)$ & $\begin{array}{l}707(265) \\
\text { ns }\end{array}$ & $724(264)$ \\
& & . & \\
\hline
\end{tabular}

HIP, high intensity protocol; LIP, low intensity protocol; $\mathrm{Vo}_{2}$, oxygen consumption.

Table 3 Neuroendocrine function (mean, median (range))

\begin{tabular}{|c|c|c|c|}
\hline & Baseline & Lisinopril & Placebo \\
\hline P ARC $(\mu \mathrm{U} / \mathrm{ml})$ & $14,12(1-34)$ & $\begin{array}{l}47,55(5-105) \\
\mathrm{p}<0.001\end{array}$ & $14,13(1-31)$ \\
\hline $\mathrm{P}$ angiotensin $\mathrm{II}(\mathrm{pg} / \mathrm{ml})$ & $10,9(4-18)$ & $\begin{array}{l}5,5(1-12) \\
p<0.02\end{array}$ & $9,7(4-19)$ \\
\hline $\mathrm{P}$ aldosterone $(\mathrm{pg} / \mathrm{ml})$ & $108,87(25-269)$ & $\begin{array}{l}85,66(19-206) \\
p<0.05\end{array}$ & $112,113(22-253)$ \\
\hline P ANP (pg/ml) & $62,52(6-187)$ & $\begin{array}{l}43,40(3-140) \\
p<0.04\end{array}$ & $63,69(13-166)$ \\
\hline P noradrenaline $(\mathrm{nmol} / \mathrm{l})$ & $2 \cdot 1,1 \cdot 8(0 \cdot 9-3 \cdot 9)$ & $2 \cdot 7,2 \cdot 2(0 \cdot 8-7 \cdot 6)$ & $2 \cdot 4,2 \cdot 1(0 \cdot 8-4 \cdot 0)$ \\
\hline $\mathrm{P}$ adrenaline $(\mathrm{nmol} / \mathrm{l})$ & $0 \cdot 2,0.2(0.1-0.4)$ & $0.3,0.2(0.1-0.7)$ & $0 \cdot 3,0 \cdot 2(0 \cdot 1-2 \cdot 0)$ \\
\hline P ADH $(\mathrm{pg} / \mathrm{ml})$ & $1.1,0.5(0.2-4.6)$ & $\begin{array}{l}0.7,0.6(0 \cdot 1-1 \cdot 4) \\
\text { nc }\end{array}$ & $0 \cdot 7,0.4(0 \cdot 2-2 \cdot 3)$ \\
\hline
\end{tabular}

$\mathrm{P}$, plasma; ARC, active renin concentration; ANP, atrial natriuretic peptide; $\mathrm{ADH}$, antidiuretic hormone; nc, significance not calculated.

Table 4 Haematological (mean (SD)) values and serum biochemistry

\begin{tabular}{|c|c|c|c|}
\hline & Baseline & Lisinopril & Placebo \\
\hline $\begin{array}{l}\text { Haemoglobin } \\
(\mathrm{g} / \mathrm{dl})\end{array}$ & $14 \cdot 6(1 \cdot 1)$ & $\begin{array}{l}14 \cdot 3(0 \cdot 8) \\
\mathrm{nc}\end{array}$ & $14.0(0.9)$ \\
\hline $\begin{array}{l}\text { White cell } \\
\text { count }\left(\times 10^{9} / 1\right)\end{array}$ & $5 \cdot 3(0 \cdot 6)$ & $\begin{array}{l}5 \cdot 0(0 \cdot 6) \\
\mathrm{nc}\end{array}$ & $5.0(0.5)$ \\
\hline $\begin{array}{l}\text { S sodium } \\
(\mathrm{mmol} / \mathrm{l})\end{array}$ & $138(3)$ & $\begin{array}{l}139(2) \\
\mathrm{nc}\end{array}$ & $139(3)$ \\
\hline $\begin{array}{c}S_{(\mathrm{mmo} / \mathrm{l})} \\
\text { potassium }\end{array}$ & $4 \cdot 3(0 \cdot 5)$ & $\begin{array}{l}4 \cdot 3(0 \cdot 4) \\
\mathrm{nc}\end{array}$ & $4 \cdot 3(0 \cdot 3)$ \\
\hline $\begin{array}{l}S \text { magnesium } \\
(\mathrm{mmol} / \mathrm{l})\end{array}$ & $0.87(0.04)$ & $\begin{array}{l}0.87(0.06) \\
\mathrm{nc}\end{array}$ & $0.86(0.04)$ \\
\hline $\begin{array}{l}\text { S phosphate } \\
(\mathrm{mmol} / \mathrm{l})\end{array}$ & $0.95(0.15)$ & $\begin{array}{l}1 \cdot 03(0 \cdot 10) \\
\text { nc }\end{array}$ & $0.97(0.09)$ \\
\hline$S$ urea $(\mathrm{mmol} / \mathrm{l})$ & $5 \cdot 8(1 \cdot 6)$ & $\begin{array}{l}6 \cdot 2(1 \cdot 3) \\
\mathrm{nc}\end{array}$ & $6 \cdot 1(1 \cdot 5)$ \\
\hline $\begin{array}{c}S \text { creatinine } \\
(\mu \mathrm{mol} / \mathrm{l})\end{array}$ & $96(14)$ & $\begin{array}{l}94(12) \\
\text { NS }\end{array}$ & $96(12)$ \\
\hline
\end{tabular}

S, serum; nc, significance not calculated. was breathlessness.

\section{Neuroendocrine function}

Treatment with lisinopril $(10 \mathrm{mg})$ once daily resulted in a decline in the plasma concentrations of angiotensin II, aldosterone, and atrial natriuretic peptide, whereas plasma concen- $\underline{\underline{\sigma}}$ trations of active renin rose (table 3 ).

Serum electrolytes, urea, and creatinine

No change in haematological or biochemical variables was found.

\section{Discussion}

The SOLVD study recently reported that $\stackrel{\mathbb{Q}}{\varrho}$ enalapril could delay or prevent symptom free is patients with impaired left ventricular func- $\overrightarrow{0}$ tion from developing overt heart failure. ${ }^{3}$ How ACE inhibitors induce such benefit is $\vec{\sigma}$ poorly understood.

\section{HAEMODYNAMIC EFFECTS}

Inhibitors of ACE could improve prognosis of by improving left ventricular function. ${ }^{9}$ In the $\vec{N}$ Second Veterans Administration Heart 음 Failure Trial (V-HeFT II) study, however, ejection fraction and exercise performance $\subseteq$ were improved to a greater extent by conven- $\bar{\phi}$ tional vasodilators and yet enalapril exerted a $\overrightarrow{0}$ greater benefit on prognosis. ${ }^{4}$

In our study lisinopril did not improve reduced resting left ventricular function, but did improve impaired maximum exercise capacity as assessed by peak oxygen consumption. Most people rarely exercise to their $\frac{\mathbb{Q}}{\circ}$ cardiorespiratory maximum, so it is not sur- $\stackrel{\overrightarrow{7}}{\overrightarrow{7}}$ prising that cardiac reserve was considerably $\frac{9}{3}$ reduced despite the lack of symptoms. High intensity protocols are known to produce greater cardiopulmonary stress and be limited more specifically by breathlessness. Patients $\underset{\mathbb{D}}{\stackrel{D}{~}}$ subjected to low intensity protocols stop exer- $\frac{7}{\sigma}$ cising for more varied reasons ${ }^{10}$ that are prob- -3 . ably more closely related to the peripheral circulation and skeletal muscle conditioning.

Dickstein et al recently reported that 0 enalapril did not improve impaired exercise? performance in patients after a myocardialo infarction, ${ }^{11}$ but all the patients in that study were taking $\beta$ blockers. Patients with evidence o of reversible ischaemia, which may be exacer- $N$ bated by ACE inhibitors, ${ }^{12}$ were excluded ${ }_{\omega}^{N}$ from both studies.

By improving cardiac reserve, ACE inhibitors may not only pull the patient back from the threshold at which heart failure ${ }^{+}$ would have occurred, but also slow the rate of $\frac{}{0}$ deterioration in ventricular function, and pre- $\overrightarrow{\mathbb{D}}$ vent heart failure appearing during further $\frac{\rho}{\mathbb{D}}$ acute insults such as atrial fibrillation.

\section{NEUROENDOCRINE EFFECTS}

Activation of neuroendocrine systems individually or in combination is associated with a흘 worse prognosis, and may contribute directly? to the progression of ventricular dysfunction. Intense activation identifies a group of patients who seem to have more to gain prognostically by treatment with an ACE 
inhibitor. ${ }^{1314}$ However, in clinically stable patients with ventricular dysfunction, which is untreated by diuretics, studies suggest that only atrial natriuretic peptide is increased before the onset of heart failure. ${ }^{4}$ Our data are consistent with this pattern of neuroendocrine activation.

Acute ventricular dysfunction induced by myocardial infarction leads to temporary activation of the renin angiotensin aldosterone system. ${ }^{15}$ Animal models suggest that such activation is reversed when the subject restores arterial pressure by vasoconstriction and salt and water retention. Thus patients with symptom free ventricular dysfunction may have tonic suppression of the renin angiotensin aldosterone system into the normal range. None the less, relative to salt and water retention and the degree of vasoconstriction values in the normal range may be inappropriately high and ACE inhibition might still be effective. If the cardiac insult is more severe or sodium retention is reversed by diuretics, activation of the renin angiotensin aldosterone system persists. ${ }^{5}$

This is the first report, as far as we are aware, on the effects of an ACE inhibitor on neuroendocrine variables in patients with ventricular dysfunction not treated with a diuretic. Lisinopril reduced plasma concentrations of angiotensin II, but plasma concentrations were not completely suppressed despite sampling three to four hours after a $10 \mathrm{mg}$ dose of lisinopril. This could reflect increased synthesis of angiotensin I and converting enzyme or alternative pathways for generation of angiotensin II. ${ }^{16}$ Great care in the handling of samples and a robust assay with a low cross reactivity with angiotensin I, makes technical error unlikely. ${ }^{17}$ Furthermore, we have shown in other studies that ACE inhibitors can reduce plasma concentrations of angiotensin II to virtually undetectable values. ${ }^{18}$

The reduction in atrial natriuretic peptide is consistent with a sustained reduction in ventricular filling pressure, but the mechanism is uncertain. No reduction in plasma noradrenaline was noted, therefore a reduction in sympathetically mediated venous tone seems unlikely. Reduced angiotensin II could have led to a fall in arterial resistance and afterload that in turn might have reduced preload, although no fall in blood pressure was noted. Alternatively, venodilatation mediated by increases in bradykinin or prostaglandins may have occurred.

\section{RENAL EFFECTS}

As in patients with overt heart failure, lisinopril increased renal blood flow ${ }^{618}$ and reduced glomerular filtration rate when assessed four to eight hours after the dose, at the time of maximum effect. Serum urea and creatinine, reflecting overall renal function, were unchanged by lisinopril, whereas serum phosphate rose only slightly. The influence of the changes in renal haemodynamic function on electrolyte and water homeostasis in patients with symptom free ventricular dysfunction have yet to be considered in detail but no change in weight occurred in this study.

In conclusion lisinopril improves cardiopulmonary reserve in patients with impaired ventricular function and may contribute to the ability of ACE inhibitors to delay or prevent the onset of overt heart failure.

We thank ICI for supplying lisinopril and matching placebo. DS was supported by a grant from ICI.

1 Cohn JN, Johnson G, Ziesche S, et al. A comparison of enalapril with hydralazine-isosorbide dinitrate in the treatment of chronic congestive heart failure. $N \mathrm{Engl} f$ Med 1991;325:303-10.

2 The SOLVD investigators. Effect of enalapril on survival in patients with reduced left ventricular ejection fractions and congestive heart failure. $N \mathrm{Engl} f \mathrm{Med}$ 1991;325:293-302.

3 The SOLVD investigators. Effect of enalapril on mortality and the development of heart failure in asymptomatic patients with reduced left ventricular ejection fractions. N Engl F Med 1992;327:685-91.

4 Francis GS, Benedict C, Johnstone DE, Kirlin PC, Nicklas J, Liang C, et al, for the SOLVD investigators. with left ventricular dysfunction with and without conwestive heart failure. Circulation 1990;82:1724-9.

5 Watkins L Jr, Burton JA, Haber E, Cane JR, Smith FW, Clifford A, Barger AC. The renin- angiotensin-aldosterone system in congestive failure in conscious dogs. $\mathcal{F}$ Clin Invest 1976;57:1606-17.

Cleland JGF, Dargie HJ, Hodsman GP, Ball SG, Robertson JIS, Morton JJ, et al. Captopril in heart failure. A double blind controlled trial. Br Heart $\mathcal{f} 1984$; 52:530-5.

7 Richards AM, Cleland JGF, Tonolo G, McIntyre GD, Leckie BJ, Dargie HJ, et al. Plasma atrial natriuretic peptide in cardiac impairment. $B M 7$ 1986;293:409-12.

8 Peters AM, Gunasekera RD, Henderson BL, Brown J, Lavender JP, De Souza M, et al. Nucl Med Commun 1987;8:823-37.

9 Giles TD, Katz R, Sullivan JM, Wolfson P, Haugland M, Kirlin $\mathrm{P}$, et al, for the multicenter lisinopril-captopril congestive heart failure study group. Short- and longacting angiotensin-converting enzyme inhibitors: a ran-
domized trial of lisinopril versus captopril in the domized trial of lisinopril versus captopril in the treatment of con

10 Lipkin DP, Canepa-Anson R, Stephens MR, PooleWilson PA. Factors determining symptoms in heart failure: comparison of fast and slow exercise tests. $\mathrm{Br}$ Heart f 1986;55:439-45.

11 Dickstein K, Barvik S, Aarsland T. Effects of long-term enalapril therapy on cardiopulmonary exercise performance after myocardial infarction. Circulation 1991; 83:1895-1904.

12 Cleland JGF, Henderson H, McLenachan J, Findlay IN, Dargie HJ. Effect of captopril, an angiotensin converting enzyme inhibitor, in patients with angina pectoris and heart failure. $₹ \mathrm{Am}$ Coll Cardiol 1991;17:733-9

13 Dargie HJ, Cleland JGF, Leckie BJ, Inglis CG, East BW, Ford I. Relation of arrhythmias and electrolyte abnorFord I. Relation of arrhythmias and electrolyte abnormalities to survival in patients with severe

14 Swedberg $K$, Eneroth P, Kjekshus J, Wilhelmsen L. Hormones regulating cardiovascular function in patients with severe congestive heart failure and their relation to mortality. Circulation 1990;82:1730-6.

15 McAlpine HM, Morton JJ, Leckie B, Rumley A, Gillen G, Dargie HJ. Neuroendocrine activation after acute myocardial infarction. $B r$ Heart $\mathcal{f} 1988 ; 60: 117-24$.

16 Urata H, Healy B, Stewart RW, Bumpus FM, Husain A Angiotensin-II forming pathways in normal and failing hearts. Circ Res 1990;66:883-90.

17 Morton J, Webb DJ. Measurement of plasma angiotensin II. Clin Sci 1985;68:483-4

18 Cleland JGF, Dargie HJ, Ball SG, Gillen G, Hodsman GP, Morton J, et al. Effects of enalapril in heart failure: a double blind study of effects on exercise performance, renal function, hormones, and metabolic state. Br Heart f 1985;54:305-12. 